\title{
APUNTES PARA UNA CORPO-POLÍTICA DESDE LAS ESCRITURAS AIMÉ CÉSAIRE Y FRANTZ FANON
}

\author{
Notes for a corpo-politics based on the writings by Aimé Césaire and Frantz
}

Fanon

\author{
Carlos Aguirre Aguirre*
}

\begin{abstract}
RESUMEN
El trabajo aborda la manera en cómo se inscribe la cuestión de la corpo-política en las obras de dos pensadores afroantillanos: Aimé Césaire y Frantz Fanon. Sostenemos que en ambos pensadores la corpo-política es una dimensión central que se vincula con sus reflexiones sobre los conflictos acaecidos entre los cuerpos colonizados con las tramas epistemológicas de la modernidad/colonialidad. Primero exploramos, desde diversos autores, la importancia de la noción de la negritud de Césaire al momento de interrogar las identidades culturales instituidas por la colonialidad sobre los cuerpos. Después indagamos la crítica de Fanon al pensamiento ontológico y a los racionalismos modernos señalando la relevancia que tienen en ésta sus planteamientos sobre el cuerpo colonizado y la zona del no ser. Concluimos que Césaire -con su concepto de la negritud- y Fanon -con su idea de la zona del no ser-cavilan otro lugar desde donde inventar una política del cuerpo poscolonial.
\end{abstract}

Palabras clave: Aimé Césaire, Frantz Fanon, corpo-política.

* Consejo Nacional de Investigaciones Científicas y Técnicas - Instituto de Filosofía, Universidad Nacional de San Juan, San Juan, Argentina (CONICET - IDEF, UNSJ). Correo electrónico: aguirreaguirrecarlos@gmail.com

Artículo recibido el 2 de marzo de 2018. Aceptado el 9 de noviembre de 2018. 


\begin{abstract}
This paper addresses the question of how corpo-politics is dealt with in the works of two Afro-Antillean thinkers: Aimé Césaire and Frantz Fanon. We contend that for both thinkers the corpo-politics is a core dimension linked to their reflections on the conflicts that took place between the colonized bodies and the epistemological schemes of modernity/coloniality. First, starting from several authors, we explore the importance of Césaire's notion of negritude, and at the same time we interrogate the cultural identities set up by coloniality on bodies. Thereafter, we conduct an inquiry about Fanon's critique of ontological thought and modern rationalisms, where we point out the importance, within this very critique, of his exposition about colonized bodies and the zone of non-being. We conclude that both Césaire's negritude concept and Fanon's idea of the zone of non-being meditate an alternative perspective from which it is possible to devise another politics on post-colonial bodies.
\end{abstract}

Keywords: Aimé Césaire, Frantz Fanon, corpo-politics.

\title{
1. Corpo-política y entre lugares
}

En el trabajo Ars Disyecta. Figuras para una corpo-politica (2014) la filósofa chilena Alejandra Castillo reflexiona sobre las prácticas político estéticas donde el cuerpo consigue infringir los espacios de contención establecidos por el moderno binarismo masculino/femenino. Amenazar el límite del cuerpo productivo parece configurar para la autora un entre lugar ${ }^{1}$ donde la política se enlaza con un ejercicio que pone en escena tanto la demanda por la igualdad, como la trasgresión de los espacios en los que el cuerpo es reconocido. Instancia doble que, "enlaza el adentro con el afuera, lo propio y lo impropio, la forma y la materia" (p. 12). Entre lugar que desintegra las tipologías monológicas. Lugar intersticial, al decir de Homi Bhabha (2002), "donde el pasado no es originario, donde el presente no es simplemente transitorio" (p. 264). Espacio liminal donde las taxonomías instituidas por la modernidad eurocentrada se incorporan de manera paródica y donde también son quebrantadas, agenciándose así una corpo-política que detiene las rígidas

\footnotetext{
${ }^{1}$ En relación al concepto del entre-lugar recomendamos ver: Aguirre, Carlos. "Pensamiento del entre-lugar y pensamiento fronterizo: (des)articulaciones y emergencias en el espacio latinoamericano", Revista Intersticios de la política y la cultura. Intervenciones latinoamericanas, 11 (2017): 69-93.
} 
oposiciones.

La corpo-política, entonces, vuelve radical la presencia de un cuerpo Otro que es siempre ilimitado y a la vez ocluido. Expone las tramas de un mundo que pretende cerrar al cuerpo de antemano y busca, en su propia proyección, trascender esas miradas que clausuran su presencia. Miradas que forman parte de lo que Michel Foucault (2014) señala como las clasificaciones -las semejanzas y las diferencias- fundadas por el pensamiento científico moderno e instauradas por la episteme de la cultura occidental las cuales fijan, corrigen, miden y supervisan la presencia de ese Otro:

La historia de la locura es la historia de lo Otro -de lo que, para una cultura, es a la vez interior y extraño y debe, por ello, excluirse (para conjurar un peligro interior), pero encerrándolo (para reducir la alteridad)-; la historia del orden de las cosas sería la historia de lo Mismo -de aquello que, para una cultura, es a la vez disperso y aparente y debe, por ello, distinguirse mediante señales y recogerse en las identidades (Foucault, 2014, p. 1).

Alteridad que no es otra cosa que un "cuerpo enfermo" para el pensamiento de la cultura occidental-imperial y, como señala el poeta cubano Roberto Fernández Retamar (2016) en su Caliban, un "cuerpo bestial” para la narrativa colonizadora ${ }^{2}$. La posibilidad de salir de los límites corporales impuestos por la norma patriarcal y la política racial colonialista, implica, si seguimos el ejercicio de Caliban, aprender la lengua del amo para después neutralizarlo y maldecirlo con "la plaga roja". En otras palabras, una corpopolítica que reconoce el espacio de lo inhumano al cual ha sido arrojado el cuerpo, y soporta el peso histórico de las violencias que lo clausuran, con el horizonte de desarticular el enclaustramiento moderno/colonial al que ha sido empujado.

En una entrevista realizada por Francisco Carballo (2015), el semiólogo argentino Walter Mignolo señala que la corpo-política del conocimiento

\footnotetext{
${ }^{2}$ En Latinoamérica diversas reflexiones filosóficas críticas han meditado al cuerpo como un espacio en el que se han diseñado cuestiones relacionadas con el racismo, la modernidad y los discursos civilizatorios europeos. Por ejemplo, el filósofo latinoamericano Leopoldo Zea ha señalado que "[los colonizadores] parten de una supuesta superioridad racial o cultural por el hecho de no ser negros o indígenas. Lo negro y lo indígena vienen a ser expresión de lo subhumano" (Zea, 1979, p. 5).
} 
no presupone un esencialismo ni un determinismo sino una opción. Para explicar esto, Mignolo apela a la obra de Fanon. Este último, al proponer una humanidad-otra frente al concepto de Hombre y de Humanidad que instituye el saber/poder de Occidente, pone en marcha "un proyecto de descolonización del humanismo eurocentrado y la construcción descolonial de la idea de humanidad" (p. 102). La negación del Hombre y de la Humanidad construida a imagen y semejanza de la masculinidad blanca europea tomará lugar en la perspectiva geopolítica y biográfica de Fanon cuando se arraiga, "en el cuerpo racializado y en las historias locales marcadas por la colonialidad" (Mignolo, 2015, p. 176). El cuerpo, entonces, como sensibilidad fronteriza capaz de desnudar la ficción que sostiene al Sujeto moderno europeo. Frontera donde el cuerpo, la política y la experiencia piensan los legados coloniales del mundo moderno. Es en ese límite donde se perfilan los cuerpos de los Otros. Donde prolifera el entre lugar, o contra-espacio, en el que se despliegan corpo-biopolíticas.

En lo que sigue, intentaremos inscribir en algunos elementos y nociones de las obras de dos pensadores afroantillanos, Aimé Césaire y Frantz Fanon, la cuestión de la corpo-política del conocimiento. En razón de esto, vemos que desde ambos autores caribeños se instituye una corpo-política que es crítica tanto del problema de la racialización como de las identidades culturales que el mundo moderno "sobredetermina" en los cuerpos. El cuerpo, como apunta Lewis Gordon (2009), deviene entonces en "un movimiento introspectivo radical" (p. 259), que, por un lado, pone en tensión los vectores utópicos -emancipadores de la modernidad, su razón histórica (Gandarilla Salgado, 2014) -advirtiendo, de esa manera, su colapso cuando la colonización de los cuerpos aparece como un problema contemporáneo-, y, por otra parte, hilvana la emergencia de una crítica caribeña que hace de la experiencia de "un cuerpo sin territorio", una sospecha emancipadora, considerando la descolonización un problema al que debemos regresar. Una corpo-política, entonces, que expande su riqueza epistemológica para develar otras zonas de las obras de Césaire y Fanon, y que ayuda a pensar una política que disuelva los clivajes 
coloniales del cuerpo.

\section{Pensar al cuerpo negro, instalar la negritud}

En el mundo moderno todo cuerpo parece estar sujeto a un régimen de normalización. Normas que vigilan constantemente la invasión de lo "anómalo" y que fortalecen las formas con las que el poder moderno/colonial atrapa a los cuerpos. Una separación dualista de las identidades en la que los cuerpos se ven involucrado: "[S]eparar lo claro (lo distinto) de lo oscuro (lo in-distinto). Para de-limitar el orden de la razón protegiéndolo contra el desorden (la confusión) de la no razón o sin razón" (Richard, 1993, p. 211). Dicho de otra manera, el etnocentrismo moderno normaliza un modo distorsionado de producir conocimiento mediante representaciones organizadas siempre en pares y de forma desigual: irracional-racional, premoderno-moderno, como también Oriente-Occidente y no-europeo-europeo. En la perspectiva de un análisis poscolonial sobre las representaciones elaboradas por Occidente, el pensador palestino-estadounidense Edward Said (2010) nota cómo la institucionalización del imaginario imperial de Oriente que Europa ha labrado en su ejercicio del poder la necesidad de integrar al "otro colonial" como objeto de estudio, tanto en imágenes, escritos y análisis.

Eduardo Grüner (2002) identifica que el pensamiento occidental necesitó construir un concepto de identidad - una metafísica de la identidadracional que finalmente se encarnó en el esencialismo y en la universalidad del individuo europeo y blanco como base del Sujeto moderno: "[L]a así llamada modernidad (a la que además habría que calificar: la modernidad burguesa) necesitó ese concepto para atribuírselo, en principio, a otro de sus inventos, fundamental desde el punto de vista ideológico: el individuo -y su expresión macroteórica: el Sujeto cartesiano” (p. 250). Así, la manera en que se fue configurando la identidad cerrada y periférica de ese Otro de Europa, de esas poblaciones que fueron desplazadas fuera de la orbe racional fundada por el discurso eurocéntrico, necesitó de una filosofía que "habría olvidado la diferencia" (Bidaseca, 2010, p. 27), y que a su vez subsumía y reordenaba al sujeto colonizado -y en nuestra contemporaneidad, al sujeto poscolonial-, "en 
los términos de una alteridad homogénea y autoconsciente" (Grüner, 2002, p. 261). Entonces, doble operación: por un lado, el Sujeto cartesiano que necesita existir para pensar-la autocrítica y el proceso dubitativo del hombre moderno racional-, y que para pensar necesita homogenizar a los cuerpos. Y, por otra parte, el desplazamiento del cuerpo del Otro a los márgenes de una identidad cerrada y consolidada por las prácticas colonialistas.

En 1934, el pensador y político martiniqués Aimé Césaire, junto a los poetas Leópold Sédar Senghor y León-Gontran Damas, crea la revista L'Étudiant Noir donde aparece el concepto de la negritud. Los intelectuales negros buscaban con esta noción: "hacer visible un mundo marcado por la enajenación cultural propia de las sociedades coloniales, así como revelarse contra la asimilación, la opresión cultural y el desprecio por la cultura de los pueblos negros" (Valdés García, 2007, p. 102). Con su primera aparición, el concepto de la negritud no patentó una doctrina ni mucho menos un programa definitivo sobre cómo enfrentar cultural y políticamente al colonialismo, sino simplemente intentó definir: "que es ser del Caribe, o de África del Sur, de Estados Unidos, de cualquier lugar donde el hombre sufre" (Ollé-Laprune, 2008 , p. 15). No obstante, y más allá de las diversas relecturas que han surgido sobre el concepto, la negritud significa también, desde nuestra perspectiva, resaltar la idea de un cuerpo atrapado por los clivajes coloniales del mundo moderno y repensar críticamente la imagen que la colonización construyó sobre el Caribe. Así, por ejemplo, lo comprende Alejandro De Oto (2011), para quien, en más de un sentido: "la imagen que resalta la negritud es la de ser "ese país de la mente" que no tiene territorio, un territorio central y para nada metafórico en términos de la política que desplegó, fue directamente la emergencia y el sostenimiento del cuerpo, del cuerpo colonizado, atrapado en las formas del poder colonial" y plantea que, "la negritud que imagina Césaire puede pensarse también como una toma de conciencia de la diferencia en tensión que expresan los cuerpos colonizados cuando buscan un espacio de enunciación que, al menos en apariencia, funcione como propio" (p. 279).

El sujeto sustancial de la modernidad, al no reconocer la subjetividad de los afectados por el colonialismo - pues desde los caracteres universalistas 
de sus postulados científicos racionales se derivó la autofundante superioridad cultural de Europa en el ámbito global- desplegó una estructura temporal lineal caracterizada por una lógica de desarrollo desde la que se medían cultural, política y económicamente a las poblaciones colonizadas. Esta racionalidad que se autodefinió como liberadora: "no estuvo incontaminada, su savia fue nutrida, desde el comienzo, 'por las relaciones de poder entre Europa y el resto del mundo"' (Gandarilla Salgado, 2017, p. 70). La aparición en 1939 del Cahier d'un retour au pays natal ${ }^{3}$ de Césaire, junto con denunciar la situación de las poblaciones sometidas por el colonialismo, diseña una interrogación que se arriesga a desplazar los límites fijos impuestos de las construcciones identitarias modernas. Esto no equivale a construir una reivindicación identitaria que teje un "esencialismo otro" del negro sino, muy por el contrario, pensamos que la intención de Césaire inaugura una noción de la negritude mucho más clara y definida que aquella propuesta en L'Étudiant Noir. Una idea en la que aparece un cuerpo que, en tanto que integra la conciencia histórica colectiva caribeña y africana, rehúye de los perímetros culturales establecidos por lo que Santiago Castro-Gómez (2008) llama "la dimensión epistémica del colonialismo" (p. 124). Podríamos sostener que, entonces, el cuerpo colonizado tal como se traza en la negritud desafía la pretensión de naturalidad y originalidad de la modernidad, mostrando la artificialidad de sus propias idealizaciones y, sea de paso, de su discurso crítico, cuando la racialización de los cuerpos aparece como una práctica ineludible en la ejecución de su proyecto económico ${ }^{4}$.

En este marco, la negritud del Cahier... se sostiene también en lo que el autor camerunés Achille Mbembe (2016) entiende como una inventiva que

\footnotetext{
${ }^{3}$ Cuaderno de un retorno al país natal.

${ }^{4}$ Césaire amplía estos problemas en lo que es uno de los trabajos más relevantes del conjunto de su obra: Discurso sobre el colonialismo, publicado por primera vez en 1950. Con una escritura distinta a la que utiliza en su Cahier..., y convirtiéndose en un futuro próximo a su aparición en el trasfondo teórico de muchos trabajos posteriores de sus colegas antillanos, principalmente de Peau noire, masques blancs (Piel negra, máscaras blancas) de Fanon, publicado en 1952, Césaire aclara que el objetivo de este texto es explorar y desenmascarar la relación entre el colonialismo europeo y la civilización. Desde esa perspectiva, el poeta sostiene a lo largo de su escrito lo gravoso que resulta para el conjunto de la humanidad los estragos materiales y espirituales que causa el colonialismo, y, fundamentalmente, una crítica vehemente al discurso humanista burgués y europeo que asemeja civilización con progreso y colonización.
} 
hace revivir un cuerpo que ha sido inmolado por el inconsciente racial de la modernidad. Si la realidad del colonialismo tuvo como uno de sus primeros fundamentos la perdida genealógica cuando se priva al esclavo negro de todo parentesco con sus orígenes, la negritud del Cahier... se dirige a construir un lazo, a "hacer surgir un lugar donde mantenerse en pie en repuesta a una larga historia de subyugación y de fractura biopolítica"(p. 77). Siguiendo este análisis, la negritud activa, salva y reactualiza la experiencia originaria de un sujeto que se ha vuelto extranjero para sí mismo. Precisamente ese ejercicio de reafirmar a la cultura negra como una cultura positiva se constituye a partir de un sentimiento de pérdida y desde la idea de una comunidad que está constantemente amenazada de exterminio. Hacer revivir al cuerpo, constituye la respuesta a un deseo de sobrevivencia: "a imaginar y propiciar otro lugar donde poder aislarse y estar protegido" (Mbembe, 2016, p. 78).

La cuestión que plantea el análisis de Mbembe es, primordialmente, pensar a la negritud como la posibilidad de reelaborar un cuerpo que ha sido marcado con un signo negativo por la cultura europea. Siguiendo a Monserrat Galceran Huguet (2016), si la relación uno/otro está siempre definida desde el uno y no reconoce nunca la heterogeneidad sino la reduce a la alteridad, la noción de la negritud parte resignificando un término que ha sido utilizado en un sentido despectivo y lo utiliza ahora en un sentido positivo: "[D]onde el discurso racista coloca desprecio, él coloca admiración" (Galceran Huguet, 2016, p. 308). Revirtiendo la operación habitual del discurso moderno/ colonial sobre los cuerpos, Césaire toma el encierro que el hombre europeo funda sobre el cuerpo negro, donde no hay otras posibilidades más que un lugar subordinado y no reconocido, y lo entrecruza conflictivamente con un cuerpo desembarazado de esa clausura, situándolo en una subjetividad móvil y no aniquilable. Este punto es importante, ya que cuanto más pareciera Césaire estar cerca de construir un "escencialismo identitario" con la negritud, la idea de hacer revivir al cuerpo colonizado la convierte en un lugar en el que es imposible la afirmación de una identidad originaria y natural. En otras palabras: si la colonialidad ha eliminado violentamente la posibilidad misma de una identificación africana a la cual retornar, aunque en el Cahier... sea una 
"insoslayable referencia originaria", la negritud de Césaire pareciera tratarse de una noción "decididamente caribeña, y no unilateralmente africana" (Grüner, 2016, p. 243), pero también consiste en un momento que explora la posibilidad de que el cuerpo colonizado, desde la experiencia histórica afrocaribeña, no solo desmonte los prejuicios biológicos que lo han oprimido sino además pueda liberarse de los binarismos modernos que han sostenido esos mismos prejuicios, pudiendo así arrojar a la luz el carácter contingente, dislocado y conflictivo que lo constituye.

De acuerdo con esto, el cuerpo colonizado se inscribe en un entre lugar pues su negritud no se encuentra ceñida a una tradición inmutable: "La negritud como una identidad política a la luz de la comprensión de cualquier identidad siempre está compuesta de manera compleja, siempre se construye históricamente. Nunca está en el mismo sitio sino que siempre es posicional" (Hall, 2010, p. 327). Ese "país de la mente"5 -alegoría con la que se enlaza la negritud de Césaire-altera la economía de un cuerpo fijado en el sentido común moderno, en su orden cultural. El cuerpo negro, entonces deviene en un sitial que se reelabora constantemente en lo que Stuart Hall (2010) entiende como "diferencia": no es la simple "otredad", es también un sentido que desafía: "las oposiciones binarias establecidas en las que se apoyan el significado y la representación, y que muestran cómo el significado nunca está terminado o completado, pero que se mantiene en movimiento para abarcar otros significados adicionales o suplementarios" (p. 354). Lo que parece conseguir esta reubicación del cuerpo colonizado más allá de los cierres arbitrarios es, en primer lugar, inscribirlo en la compleja identidad cultural del Caribe y, a su vez, hacer de la negritud una voz de resistencia que, en tanto lugar de reconfiguración cultural, diagrama una corpo-política del conocimiento que nombra al cuerpo por fuera de la noción moderna de Sujeto. La negritud sería

\footnotetext{
${ }^{5}$ Benita Parry es quien más ha reflexionado a la negritud como una construcción cultural que arroja a la luz el carácter dislocado y mestizo de la identidad negra, y en la que: "emerge una visión del África más cercana a un 'artificio' o 'pasaje de la mente”' (Mellino, 2008, p. 59). Esto ha permitido conectar a Césaire con las cavilaciones de Bhabha y Hall sobre el carácter diaspórico y rizomático de las formaciones culturales.
} 
así un lugar que altera la norma colonizadora y sus restricciones corporales. Revela, de modo explícito, la colonialidad que cruza al cuerpo y que es a la vez rechazada por el mismo.

Quizás es precisamente esto último lo que permite a Césaire cavilar en 1987 a la negritud como un reintegro de la cuestión de la colonización en el presente: "Una identidad no como un arcaísmo devoradora de sí misma, sino devoradora del mundo, es decir, que se apodera sobre todo del presente para mejor reevaluar el pasado y, más aún, para reparar el futuro" (Césaire, 2006, p. 90). En consecuencia, si la negritud ha de tener un futuro, éste será el de una corpo-política que asuma la complejidad de dinámicas culturales que se mueven ambivalentemente hacia nuevos significados, algunos más resistentes que otros, en el escenario global de la colonialidad. Un cuerpo que renuncia a pensar una alternativa descolonizadora desde la racionalidad liberadora levantada por la modernidad.

Ante lo expuesto, la idea de esta corpo-política desafía en más de un sentido el imaginario occidental donde el cuerpo: "se transforma en fuerza de utilidad cuando es, al mismo tiempo, cuerpo productivo y cuerpo sometido" (Browne Sartori, 2013, p. 95). Un cuerpo que es sometido colonialmente por estrategias de control racistas que certifican violentamente la hegemonía cultural europea. Así, en una corpo-política trazada desde la negritud, ese cuerpo periférico descentra la economía eurocéntrica de los cuerpos que esgrime: "técnicas y discursos científicos, dando verosimilitud y coherencia a las normas ‘ético-morales' del humanismo y la modernidad” (Browne Sartori, 2013 , p. 96). No consiste, en consecuencia, en rastrear un supuesto metafísico "perdido" en los cuerpos colonizados, ni mucho menos en traducir desde la periferia el valor de autoridad única que se autoasignó el centro metropolitano. Se trata, más que todo, de una crítica que presenta atención a la cuestión de la colonialidad de los cuerpos desde las fallas, en el orden de la cultura y el lenguaje, de la modernidad occidental. Es crucial en esto poder leer a esta corpo-política desde lo que Carlos A. Jáuregui (2005) llama como assimilation: "término usado en la retórica oficial del colonialismo francés y resignificado desde la periferia caribeña" (p. 703). Creemos que esto conlleva no solo a reflexionar 
la negritud como: "una especie de calibanismo/canibalismo cultural", pues: "Assimiler es para Césaire ingestión activa de la cultura occidental europea y una práctica antropofágica de resistencia a ser asimilado" (Jáuregui, 2005, p. 703), sino, además, pensar la articulación política de los cuerpos en un espacio geográfico -el Caribe- que se ha configurado en choques y mixturas culturales que se resisten al modelo cultural único modulado por la discriminación racial contemporánea. La negritud como un ejercicio: "que reconoce que las identidades del Caribe no están en el pasado sino en las luchas del presente" (Jáuregui, 2015, p. 702), y también como un locus contracolonial que habla desde la conflictiva diversidad de los cuerpos.

Vista así, la corpo-política del conocimiento que tiene lugar en la negritud del poeta antillano camina en la dirección de alterar sistemáticamente los lugares fijos, preconstituidos y uniformes del orden moderno/colonial. Con acierto, Valdés García (2017) apunta que la negritud: "como concepto, surgido desde el imput antillano, constituye una herramienta que descubre una perspectiva distinta; una realidad ocultada por el pensamiento occidental" (p. 118). Se trata de un desocultamiento de las tramas y los discursos que hicieron posible la universalidad de una historia que se planteaba como única y soberana, sostenida por un modelo de identidad que dividió al mundo moderno entre cuerpos que existen y cuerpos que no existen. Esa versión eurocéntrica oficial para la cual Latinoamérica y el Caribe son: "una suerte de 'exterioridad exótica' con la cual, al parecer, el occidente europeo (y, desde hace más de un siglo, su heredero norteamericano) nada tiene que ver, como si la civilización capitalista europea se hubiera autoengendrado, hubiera salido de la nada" (Grüner, 2010, p. 74).

\section{El cuerpo en la zona del no ser}

Cuerpo y modernidad son conceptos que, a nuestro modo, sintetizan parte importante de la analítica sobre los modos culturales e ideológicos instalados por el mundo colonial que se desprende de los trabajos del autor caribeño Frantz Fanon. Se puede señalar que en el pensamiento contemporáneo del Caribe francófono, principalmente en los textos de un autor como Fanon, 
el problema del cuerpo aparece como una constante desde la que se desglosan algunas vetas epistemológicas para comprender el enlace entre mundo moderno y los brutales mecanismos de sujeción colonial. Pensemos, por ejemplo, en las discusiones de Fanon sobre la experiencia cultural del colonizado negro desde la perspectiva que el mismo llama como lo sociogénico en su obra Piel negras, máscaras blancas de 1952. Si lo ontogénico se refiere al organismo individual y la perspectiva filogénica se refiere a la especie, como bien explica Lewis Gordon (2009), lo sociogénico se refiere: "a lo que emerge del mundo de lo social, el mundo intersubjetivo de la cultura, la historia, el lenguaje, o la economía" (p. 220). Mignolo (2009) dirá que lo sociogénico en Fanon es lo que permite desprendernos: "de la hegemonía filogenética en el ámbito de la biología y de la neurofisiología, y de la perspectiva ontogenética en el ámbito del psicoanálisis" (p. 321). Así, con lo sociogénico nos encontramos frente a una: "analítica de la lógica de la colonialidad escondida bajo la retórica de la modernidad" (Mignolo, 2009b, p. 15), y que en Fanon se hilvana fundamentalmente en su crítica a los fundamentos biológicos y ontológicos desde los que el colonialismo trama la superioridad de los blancos frente a los negros. Un principio que: "al surgir de la "experiencia del hombre negro' despega también el concepto de ser humano modelado a partir de 'la experiencia del hombre blanco'" (Mignolo, 2009b, p. 319).

Empero, si, desde la perspectiva decolonial, en lo sociogénico es posible inquirir un desprendimiento -un de-linking epistémico ${ }^{6}$ - de los principios civilizatorios de la colonialidad, creemos, a su vez, que en Fanon es la experiencia del cuerpo colonizado la que se constituye como una dimensión que puede destramar una colonialidad del ser que: "se asienta sobre la mirada como momento constitutivo de la diferencia colonial, de la sujeción universal,

\footnotetext{
${ }^{6}$ El concepto de de-linking es propuesto por Mignolo para referirse a la descolonización epistémica, o al "vuelco epistémico decolonial", que tiene por horizonte la construcción de una universalidad-otra. A diferencia del de-linking formulado por Samir Amin que solo se refiere al desprendimiento económico del capitalismo, el de-linking decolonial supone un desprendimiento de la matriz colonial del poder y de todas sus esferas (culturales, económicas, políticas, culturales, epistemológicas, etc). Para más detalles ver: Mignolo, Walter. Desobediencia epistémica: Retórica de la modernidad, lógica de la colonialidad y gramática de la descolonialidad, Buenos Aires: Del Signo, 2010.
} 
que es absolutizado por la violencia" (Bidaseca, 2010, p. 58). Nelson Maldonado-Torres (2006) apunta sobre la noción de la colonialidad del ser que ésta puede llegar a ser: "una posible manera de teorizar los fundamentos básicos de las patologías del poder imperial y la persistencia de la colonialidad" ( $p$. 106). Seguramente la cuestión del cuerpo colonizado se encuentra involucrada en la configuración de una colonialidad que necesita a toda costa producir una violencia ontológica desde la que se han desplegado las formas modernas de racismo que Fanon dilucidó. Ahora bien, al hablar del cuerpo colonizado en la obra de Fanon estamos aludiendo a un asunto que es mucho más complejo que rastrear si el pensador afrocaribeño se circunscribe al extenso crisol de saberes que responden críticamente frente a una geopolítica del conocimiento imperial. Es por esto que la pregunta que se hace Karina Bidaseca (2010) sobre si es posible descolonizar al sujeto que ha sido racializado por el otro imperial hace eco en la cuestión de la experiencia del cuerpo colonizado, desde la que pensamos que se abre la posibilidad de darle un sentido descolonial a la corpopolítica biográfica de Fanon: “¿Cómo lograr la descolonización de un cuerpo colonizado en el que 'sabiamente se había inculcado el miedo, el complejo de inferioridad, el temblor, la genuflexión, la desesperación, el servilismo'?" (Bidaseca, 2010, p. 58). Si el colonizado está trazado de antemano por los discursos que han cruzado a la razón moderna ${ }^{7}$, entonces surgen estas interrogantes referidas a cuáles son las posibilidades de que su cuerpo pueda interrogarse la coraza epistémica que se le ha impuesto. En otras palabras, ¿es

\footnotetext{
7 Tanto en la obra de Césaire como en la de Fanon es posible encontrar una crítica a la certeza absoluta del método cartesiano. En este sentido, las lecturas anticoloniales de ambos pensadores, pero fundamentalmente la Fanon, permiten explicar la relación indisociable que acaece entre un método que se encuentra dominado por directrices epistemológicas que prescinden del contexto histórico con la encrucijada colonial que abre ese mismo método. $\mathrm{Si}$ el camino a la verdad que busca el método cartesiano dio sustento a esa perspectiva limitada y reduccionista de Occidente, la cual configuró una prescripción sagrada de cómo debe ser el mundo, no es de extrañar, pues, que la crítica contemporánea del Caribe -esa área cultural que ha sufrido con mayor vehemencia la consecuencia del colonialismo- es la que pone en entredicho tales supuestos desde las experiencias de los cuerpos racializados. Césaire y Fanon, entonces, no buscan mostrar, desde una visión nostálgica, los impasses coloniales del método cartesiano, no mucho menos sustentar una lectura desde donde se piense a una modernidad desviada de su proyecto emancipador, sino sugieren, desde los diversos problemas de orden cultural y político que abordan, cómo las producciones epistemológicas del mundo moderno necesitan racializar a los cuerpos y convertirlos en fuerza de trabajo explotada para conseguir sus fines.
} 
posible que el cuerpo devenga en experiencia en un mundo donde se la han cercenado sus interrogaciones? $\mathrm{O}, \mathrm{y}$ en relación a nuestra exposición, ¿es posible delinear una corpo-política del conocimiento desde la crítica de Fanon al colonialismo? Para ello, Fanon destruye: "los ídolos que militan contra el espíritu humano en un mundo de racismo antinegro" (Gordon, 2009, p. 222).

Fanon, al igual que Césaire, no ofrece una política -o un programa revolucionario articulado en el lenguaje de los discursos políticos anticoloniales de mitad del siglo XX- que declare "racionalmente" cómo liberarse de la trabas culturales y existenciales que han fijado al colonizado en el espacio de lo no-humano. Sin embargo, lo que se puede definir como una política descolonizadora, junto con la puesta en tensión de los lineamientos ontológicos del mundo moderno, encuentran lugar en sus discusiones sobre el cuerpo colonizado en Piel negras, máscaras blancas. A propósito de esto, De Oto (2013) apunta que: "Fanon, muy temprano en su obra, comprende que lo que está en juego en la descolonización es una discusión acerca de los cuerpos que el colonialismo configura, porque son el lugar donde se concentran tanto las articulaciones de la lengua colonial como también las estructuras de dominación" ( $p$ 79). Se trata, fundamentalmente, de entender al cuerpo como una experiencia que escenifica la inadecuación del sujeto racializado frente a las definiciones ontológicas y como un trayecto donde el colonizado asume trágicamente su lugar subalterno dentro de la realidad colonial de la historia presente.

Escribe Fanon (2009) que: "[1]a ontología, cuando de una vez por todas se admite que deja de lado la existencia, no nos permite comprender el ser del negro" (p. 111). La ontología presupone un centro habitado por una verdad que trata de dar cuenta de toda la complejidad del sistema moderno occidental. Por ende, estructurar una forma tiempo y espacio, presuponer un concepto de ser humano definitivo, delimitar cuál es el origen del pensamiento y, en razón de esto, poder alcanzarlo, fueron formulaciones y prácticas que delinearon un sistema que se (auto)consideró como completo y que alcanzaría todos los niveles de la vida humana. No parece casual, en efecto, que cuando la ontología pretendió explicar a la otredad terminó por forjar un lugar certero desde el que 
se trazó una retórica de lo propio donde se demarcaron los límites entre quienes forman parte de la primacía del saber y quienes no. Lo que Jacques Derrida (1997) entiende como el equilibrio establecido de: "un sistema dado, un índice anhistórico y radicalmente homogéneo" (p. 10). Frente a ello, el cuerpo en Fanon como diferencia y experiencia ha de cuestionar las certezas de un orden ontológico fundado en el valor del origen y en una "lógica de la identidad". El cuerpo colonizado como emergencia de nuevos modos de delinear el presente, como caldera de una nueva subjetividad, y como: "movimiento 'productivo' y conflictual al que ninguna identidad, ninguna unidad, ninguna simplicidad originaria podría preceder" (Derrida, 1997, p. 11).

$\mathrm{Y}$ en esto, es preciso operar, ciertamente, dentro del sistema que le da certeza a las racionalizaciones del mundo moderno/colonial. En esta línea, el cuerpo que ontológicamente es fijado, reconocido y tramado dentro del principio de realidad blanco rápidamente es desmantelado y expulsado cuando el conocimiento del mismo se vuelve: "una actividad únicamente negadora" (De Oto, 2013, p. 112); "Instabilidades -dice De Oto (2013)que pueden llegar al extremo de hacer desaparecer el mundo explicado por esa lengua (la colonial) o ponerla en entredicho" (p. 78). Los mecanismos de sujeción colonial no se mueven en un solo punto, ni mucho menos se mantienen bajo un solo lugar. Entonces, la pregunta que queda suspendida acá es, nuevamente, cómo se motiva una política en los sitiales de la esterilidad epistémica asfixiante del colonialismo. Fanon procede rastreando lo que él llama esquema histórico-racial: "Los elementos que había utilizado no me los habían proporcionado 'los residuos de sensaciones y percepciones de orden sobre todo táctil, vestibular, quinestésico y visual', sino el otro, el blanco, que me había tejido con mil detalles, anécdotas y relatos" (Fanon, 2009, p. 112). Un reconocimiento que se establece en función de que el cuerpo colonizado se ajuste a las leyendas y las historias del mundo blanco. A esta condición subalterna del cuerpo, Fanon le agrega el esquema epidérmico-racial: "que responde ya a la misma imposibilidad de imaginar una existencia en las relaciones sociales para ese cuerpo en el ambiente histórico y social del colonialismo, donde lo que está en juego es su rechazo liso y llano" (De Oto, 
2008, p. 80). Es decir, una existencia que no es tal y un cierre imperioso del reconocimiento. Como señala Fanon (2009) acerca de su propia experiencia: "Ya no me divertía tanto. Ya no descubría las coordenadas febriles de mundo. Existía triple: ocupaba sitio. Iba hacia el otro... y el otro evanescente, hostil, pero no opaco, transparente, ausente, desaparecía. La náusea..." (p. 113). Un cuerpo que parece haber fracasado en su búsqueda de solidaridad. Si las representaciones realizadas por el colonialismo se caen, las ontologías de la identidad del mundo occidental poco tienen que decir sobre los cuerpos. ¿Qué pasa, entonces, con esta trágica huida del cuerpo colonizado de las tramas de la representación?

La articulación histórica de la modernidad/colonialidad se despliega en un espacio que excluye todo lo que no forme parte de su limitada promesa de universalidad. Esto obliga a pensar lo que Lewis Gordon (2009) le llama el continuo autoengaño de la civilización occidental. El filósofo afroamericano explica esto a partir del fracaso que tiene la consecución de un proyecto que, buscando estabilizarse como una teodicea universal, rápidamente toma forma de negación social. Dice Gordon que: "[1]a gente de color, en particular los negros, experimentaron las contradicciones de este continuo autoengaño", para más adelante agregar que: “[e]sta contradicción emergió debido a que una condición que a menudo se impone a las personas de color es que acepten los principios de la civilización occidental sin comportarse como seres críticos" (p. 218). En ese sentido, es necesario pensar a la huida del cuerpo colonizado no como una política que es incapaz de rescatar a las figuras culturales excluidas por la modernidad/colonialidad sino todo lo contrario. El asunto es que ese rescate, como, por ejemplo, lo hace Fanon con la negritud de Césaire y fundamentalmente de Senghor, se ejecuta en una lógica que desestabiliza los axiomáticos esencialismos modernos. Es por esto que en su trabajo los límites se escriben y se borran continuamente, pues de lo que se trata es de imaginar una corpo-política más allá de las lógicas de saber-poder de lo que décadas posteriores a su muerte se pensará en Latinoamérica como colonialidad.

Con esto, por supuesto, Fanon no desconoce las articulaciones históricas que habitan en la sociedad colonial. Desde su apoyo a la candidatura comunista 
de Césaire en 1946 a la gobernación de Martinica hasta su labor como médico y escritor en el Frente de Liberación Nacional de Argelia (FLN) en los años 50 , por solo nombrar algunos hechos, son pruebas claras de la sensibilidad que tuvo durante toda su vida por las formas históricas que Europa impuso en las sociedades colonizadas. Empero, cuando le toca analizar la naturaleza del colonialismo, nota que el espacio histórico en el que se ha articulado no es el lugar de lo común, ni mucho menos un lugar plausible para que se desprenda rápidamente una política descolonizadora. El punto es que mientras se siga articulando la política en el marco de las posibilidades reales y biológicas diagramadas por el colonialismo el resultado será una suerte de estabilización del principio de realidad blanco, o, mejor dicho, una reproducción de los moldes culturales de la modernidad/colonialidad blanca. Así lo demuestran, por lo menos, los distintos pasajes autobiográficos que Fanon narra en el curso de Piel negras, máscaras blancas. La zona del no ser expuesta en esta obra será así la oportunidad de escapar del tiempo de las representaciones modernas y de las ontologías. El lugar de la inadecuación desde donde se reflexiona tanto al cuerpo como a la política. Como expresan Alejandro De Oto y Leticia Katzer (2014), se trata de una zona: "en las que operaciones usuales de la representación, de las ontologías estabilizadoras de la existencia, se sacuden a favor de un territorio más pleno de incertidumbres y de riesgos pero menos tramado, menos estriado por los dominios del concepto en tanto que acontecimiento, y de la categoría en tanto que representación" (p. 57). Esa es la razón por qué este esta zona se sitúa en el movedizo lugar de una experiencia que desestabiliza: "las tramas de la representación y del dualismo mortífero en el que organiza la corporalidad colonial, entre blancos y negros, o diríamos también, entre blancos e indios, entre civilizados y bárbaros" (De Oto y Katzer, 2014, p. 57).

El cuerpo ya no es representado en tanto animalidad, en tanto no sujeto. No es el cuerpo anclado en las operaciones opresivas de la razón, ni en las prefiguraciones biopolíticas de la modernidad. Es el cuerpo en su devenir político el que destruye sistemáticamente los valores del universalismo anclado en los discursos humanistas europeos y sus políticas de reconocimiento. 
La estrategia de Fanon es, de este modo, asegurar un espacio desde donde iniciar una corpo-política de la existencia del colonizado. Si el discurso humanista ha caído en una razón paternalista que tiene por horizonte reinsertar al cuerpo negro en el movimiento superador de la dialéctica, como intentó hacerlo Sartre en su célebre Orphé Noir ${ }^{8}$, la zona del no ser es lo contrario de lo que se entiende como un repliegue hacia las certezas de la razón. Por el contrario, es el espacio de las posibilidades políticas de un cuerpo que excede los entornos trascendentales. Lugar donde ese cuerpo poscolonial postula nuevas estrategias críticas. Así lo deja entrever Gordon (2009) cuando señala que Fanon: "[i]nvita a su cuerpo a liberarse de las patologías sociales en pos de la expresión que mejor representa su conciencia madura y libre: la crítica" (p. 256). En esto, pensamos, junto con Gordon, que Fanon introduce la importancia de la experiencia, de lo accional, en una perspectiva filosófica existencialista que insiste en el papel del presente (Gordon, 2009). Lo que importa, entonces, es señalar qué zona del no ser es el espacio del que se vale Fanon para leer la cuestión del cuerpo contra cualquier retórica usual de la representación histórica y trascendente del logos. Pensamos así que es en ese lugar donde se trama una corpo-política desde la que se inscribe una crítica de orden epistemológico. En esa apertura es donde se puede pensar más allá de los binarismos opresivos de la modernidad/colonialidad y de todas sus eventuales delimitaciones. Enfatizar esto desde la zona del no ser facilita, pensamos, una tarea descolonizadora capaz de reinventar la máxima: “¡Oh, cuerpo mío, haz de mí siempre un hombre que interroga!" (Fanon, 2009, p. 190) con la que Fanon termina Piel negras, máscaras blancas en un contexto donde aún predomina el supuesto de que todo estaría perdido.

\section{La radicalidad de la sospecha corpo-política}

Permanecer más allá del racismo estructural asentado por el colonialismo implica hacer del cuerpo una zona que nos remite a otro lugar. Este espacio puede ser el de una corpo-política que no solo posibilité reforzar

\footnotetext{
8 Orfeo Negro.
} 
la enunciación crítica sobre las características negativas que el colonialismo ha asentado en los cuerpos, sino también inventar y trasformar al cuerpo mismo bajo un contexto donde las restricciones de la colonialidad se asientan en la sistemática aniquilación cultural y política de todo lo que no esté sujeto a su modelo de existencia. En otras palabras, desocultar cómo la colonialidad es una esfera constitutiva de la modernidad que ha permanecido inalterada en los cuerpos incluso después del declive político formal del colonialismo. Las críticas anticoloniales de Césaire y Fanon, como pudimos ver, nos insinúan que esa colonialidad se fija en los cuerpos como una condición que escapa del control de los colonizados, como rasgos de un saber-poder que ellos no pueden seleccionar a su antojo. Es preciso, entonces, pensar la sospecha corpo-política como un acto que en el "aquí y ahora" de Latinoamericana y el Caribe se cuestiona el proceso de lo político. Un "aquí y ahora” que se trama en el cuerpo, en su experiencia vivida, en su situación espacial periférica. Si la colonialidad nos ha forzado a asumir nuestra existencia política como la parte denegada y herida de la historia "universal", es hora de que: "les señalemos con el dedo que esa herida no cesa de sangrar" (Grüner, 2002, p. 376).

La herida emana de un cuerpo que indefectiblemente se encuentra ligado con las tramas epistemológicas del "Centro" en una relación de asimetría casi permanente. Por eso, la corpo-política es sospecha. Desconfía de la cultura oficial de Occidente cuando su violencia ha llegado a los límites extremos del cuerpo. Cuerpo como lugar de infracciones, pero también de invenciones que combinan lo ocluido y lo que está por venir. Entre lugar que trasgrede los límites impuestos por una colonialidad que arroja a los cuerpos colonizados fuera de la (falsa) comunidad humana. Césaire con la negritud y Fanon con la zona del no ser representan una infracción pues están trazando otro lugar desde donde inventar al cuerpo: "Sacudir al cuerpo colonial no es llamarlo a la rebelión, no es pedir su reconocimiento, ni postular el yugo que los constituye. Es disolverlo" (De Oto, 2009, p. 45). Si las metáforas, las historias y las superficies del cuerpo colonial han sido tramadas de antemano, de lo que se trata, entonces, es de delinear la política ahí donde, por ejemplo, Judith Butler (2015) piensa la pluralidad de cuerpos en prácticas de resistencia: "Donde los 
cuerpos se juntan para mostrar precisamente que son cuerpos, y para hacer que se sepa lo que políticamente quiere decir persistir en este mundo como cuerpo" (p. 57). Un espacio de la experiencia que se rehúsa a ser captado por las identidades ontológicas.

\section{Referencias}

Aguirre, C. (2017). "Pensamiento del entre-lugar y pensamiento fronterizo: (des)articulaciones y emergencias en el espacio latinoamericano", Revista Intersticios de la política y la cultura. Intervenciones latinoamericanas, 11, pp. 69-93.

Bhabha, H. (2002). El lugar en la cultura, Buenos Aires: Manantial.

Bidaseca, K. (2010). Perturbando el texto colonial: Los estudios (pos) coloniales en América Latina. Buenos Aires: Editorial SB.

Browne Sartori, R. (2013). No al canibalismo. Anatomía del poder euroccidental. Temuco: Ediciones Universidad de La Frontera.

Butler, J. (2015). “"Nosotros el pueblo’. Apuntes sobre la libertad de reunión”. En Butler, J., Bourdieu P., Didi-Huberman., G; Khiari, S y otros. ¿Qué es el pueblo? Santiago: LOM Ediciones, pp. 41-60.

Castillo, A. (2014). Ars Disyecta. Figuras para una corpo-política. Santiago: Palinodia.

Castro-Gómez, S. (2008). "El lado oscuro de la 'época clásica', filosofía, ilustración y colonialidad en el siglo XVIII”. En Mignolo W. (Comp.). El color de la razón: racismo epistemológico y razón imperial. Buenos Aires: Del Signo, pp. 119-152. 
Césaire, A. (1963). Cuaderno de un retorno al país natal, México: ERA.

Césaire, A. (2006). Discurso sobre el colonialismo. Madrid: Akal.

De Oto, A. (2009). "Introducción. Teorías fuertes. Frantz Fanon y la descolonización como política”. En Mignolo W. (Comp.). La teoría política en la encrucijada descolonial. Buenos Aires: Del Signo, pp. 19-50.

De Oto, A. (2011). “Aimé Césaire: poética y política de la descolonización”. En Olalla M. (Coord.), Arpini A. y Jalif de Bertranou C. (Dir.). Diversidad e integración en nuestra América. Volumen II. De la modernización a la liberación: 1880-1960. Buenos Aires: Biblos, pp. 277-292.

De Oto, A. (2013). "Lugares fanonianos de la política: de la lengua al cuerpo y del cuerpo a la cultura nacional". En Olivia E., Stecher L. y Zapata C. (Eds.). Frantz Fanon desde América Latina: lecturas contemporáneas de un pensador del siglo XX. Buenos Aires: Corregidor, pp. 67-96.

De Oto, A. y Katzer, L. (2014). "Tras la huella del acontecimiento: entre la zona del no ser y la ausencia radical", Utopía y Praxis Latinoamericana, 19 (65), pp. 53-64.

Derrida, J. (1997). La diseminación, Madrid: Esprial / Ensayo.

Fanon, F. (2009). Piel negra, máscaras blancas. Madrid: Akal.

Fernández Retamar, R. (2016). Caliban y otros ensayos. Holguín: Ediciones Holguín.

Foucault, M. (2014). Las palabras y las cosas, Buenos Aires: Siglo Veintiuno Editores, 
Galceran Huguet, M. (2016). La bárbara Europa. Una mirada desde el poscolonialismo y la descolonialidad, Madrid: Traficantes de Sueños.

Gandarilla Salgado, J. G. (2014). Modernidad, crisis y crítica. Santiago: Palinodia.

García Valdés, F. (2017). La in-disciplina de Caliban. Filosofía en el Caribe más allá de la academia, La Habana: Editorial filosofi@.cu.

Gordon, L. (2009). "A través de la zona del no ser. Una lectura de Piel negra, máscaras blancas en la celebración del octogésimo aniversario del nacimiento de Fanon". En Fanon F. Piel negra, máscaras blancas. Madrid: Akal, pp. 217-260.

Grüner, E. (2002). El fin de las pequeñas historias. De los estudios culturales al retorno (imposible) de lo trágico. Buenos Aires: Siglo Veintiuno Editores.

Grüner, E. (2010). La oscuridad y las luces. Capitalismo, cultura y revolución. Buenos Aires: Edhasa.

Grüner, E. (2016). "Negro sobre blanco. Genealogías Críticas Anticoloniales en el Triángulo Atlántico: el Concepto de Negritud en la Literatura". En Bidaseca K. (Coord.). Genealogías críticas de la colonialidad en América Latina, Africa, Oriente. Buenos Aires: CLACSO, pp. 217262.

Hall, S. (2010). "Identidad cultural y diáspora". En Hall S. Sin garantias: Trayectorias y problemáticas en estudios culturales. Popayán: Envión editores, pp. 349-362. 
Jáuregui, C. A. (2005). Canibalia. Canibalismo, calibanismo, antropofagia cultural y consumo en América Latina, La Habana: Fondo Editorial Casa de las Américas.

Maldonado-Torres, N. (2006). "La topología del ser y la geopolítica del saber. Modernidad, imperio, colonialidad". En Mignolo W., MaldonadoTorres N. y Shiwy F. Des-colonialidad del ser y del saber. (videos indígenas y los límites coloniales de la izquierda) en Bolivia. Buenos Aires: Del Signo, pp. 63-130.

Mellino, M. (2008). La crítica poscolonial: descolonización, capitalismo y cosmopolitismo en los estudios poscoloniales. Buenos Aires: Paidós.

Mignolo, W.(2009a). "Frantz Fanon y la opción decolonial: el conocimiento y lo político". En Fanon F. Piel negra, máscaras blancas. Madrid: Akal, pp. 309-326.

Mignolo, W. (2009b). La teoría política en la encrucijada descolonial, Buenos Aires: Del Signo.

Mignolo, Walter(2010). Desobediencia epistémica: Retórica de la modernidad, lógica de la colonialidad y gramática de la descolonialidad, Buenos Aires: Del Signo.

Mignolo, W. (2015). Habitar la frontera. Sentir y pensar la descolonialidad (Antología, 1999-2014). Barcelona: CIDOB.

Mbembe, A. (2016). Crítica de la razón negra. Buenos Aires: Futuro Anterior Ediciones. 
Ollé-Laprune, P. (2008). "El poeta de la palabra hermosa como el oxígeno naciente: Aimé Césaire". En Ollé-Laprune P. (selec.). Para leer a Aimé Césaire. México D.F.: Fondo de Cultura Económica, pp. 9-30.

Richard, N. (1993). "Alteridad y descentramientos culturales", Revista Chilena de Literatura, 42, pp. 209-215.

Said, E. (2010). Orientalismo, Barcelona: DeBolsillo.

Zea, L. (1979). Negritud e indigenismo, México D. F.: Universidad Nacional Autónoma de México. Coordinación de Humanidades. Centro de Estudios Latinoamericanos. Facultad de Filosofía y Letras. 